\title{
Baseline Graphite Initial Mechanical Test Report
}

\author{
Mark Carroll \\ Randy Lloyd
}

September 2009
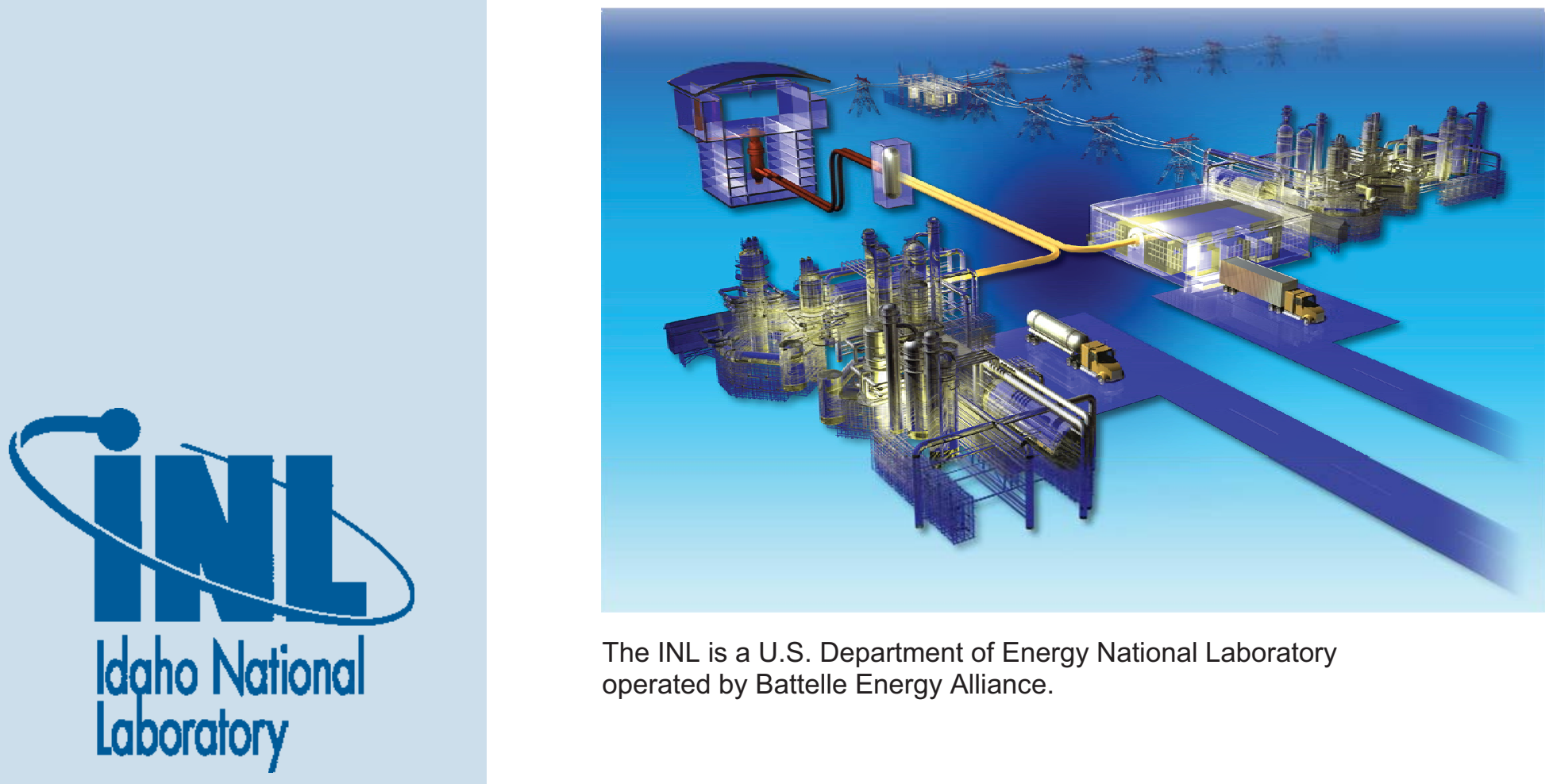

The INL is a U.S. Department of Energy National Laboratory operated by Battelle Energy Alliance. 


\section{DISCLAIMER}

This information was prepared as an account of work sponsored by an agency of the U.S. Government. Neither the U.S. Government nor any agency thereof, nor any of their employees, makes any warranty, expressed or implied, or assumes any legal liability or responsibility for the accuracy, completeness, or usefulness, of any information, apparatus, product, or process disclosed, or represents that its use would not infringe privately owned rights. References herein to any specific commercial product, process, or service by trade name, trade mark, manufacturer, or otherwise, does not necessarily constitute or imply its endorsement, recommendation, or favoring by the U.S. Government or any agency thereof. The views and opinions of authors expressed herein do not necessarily state or reflect those of the U.S. Government or any agency thereof. 
INL/EXT-09-16868

\title{
Baseline Graphite Initial Mechanical Test Report
}

\author{
Mark Carroll \\ Randy Lloyd
}

September 2009

Idaho National Laboratory

Next Generation Nuclear Plant Project

Idaho Falls, Idaho 83415

Prepared for the

U.S. Department of Energy

Office of Nuclear Energy

Under DOE Idaho Operations Office

Contract DE-AC07-05ID14517 



\title{
Next Generation Nuclear Plant Project
}

\section{Baseline Graphite Initial Mechanical Test Report}

\author{
INL/EXT-09-16868
}

September 2009

Approved by:

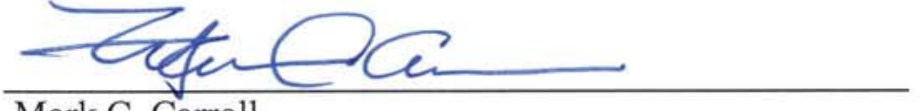

Mark C. Carroll

NGNP Staff Scientist

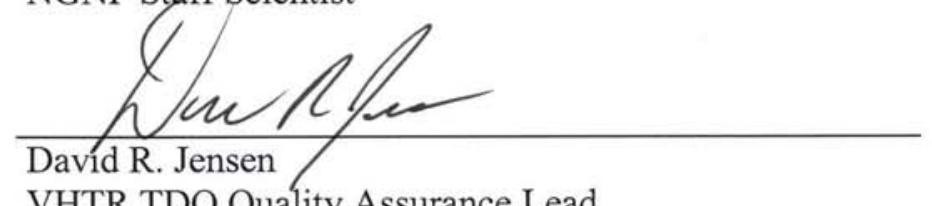

VHTR TDO Quality Assurance Lead

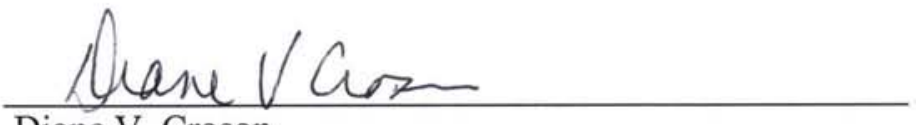

Diane V. Croson

VHTR TDO Project Manager

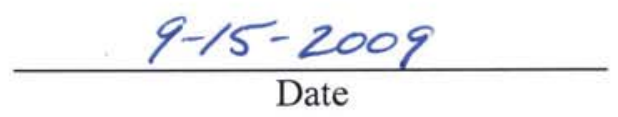

$9 / 15109$ Date

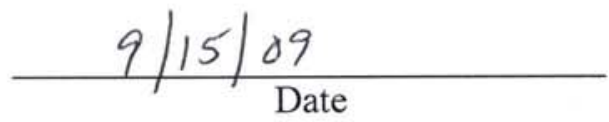





\section{SUMMARY}

The Next Generation Nuclear Plant (NGNP) Project is tasked with selecting a high temperature gas reactor technology that will be capable of generating electricity and supplying large amounts of process heat. The NGNP is presently being designed as a helium-cooled high temperature gas reactor (HTGR) with a large graphite core. The graphite baseline characterization project is conducting the research and development (R\&D) activities deemed necessary to fully qualify nuclear-grade graphite for use in the NGNP reactor. One of the major fundamental objectives of the project is establishing nonirradiated thermomechanical and thermophysical properties by characterizing lot-to-lot and billet-to-billet variations (for probabilistic baseline data needs) through extensive data collection and statistical analysis.

The reactor core will be made up of stacks of graphite moderator blocks. In order to gain a more comprehensive understanding of the varying characteristics in a wide range of suitable graphites, any of which can be classified as "nuclear grade," an experimental program has been initiated to develop an extensive database of the baseline characteristics of numerous candidate graphites.

Various factors known to affect the properties of graphite will be investigated, including specimen size, spatial location within a graphite billet, specimen orientation within a billet (either parallel to $[\mathrm{P}]$ or transverse to $[\mathrm{T}]$ the long axis of the as-produced billet), and billet-to-billet variations within a lot or across different production lots. Because each data point is based on a certain position within a given billet of graphite, particular attention must be paid to the traceability of each specimen and its spatial location and orientation within each billet.

The evaluation of these properties is discussed in the Graphite Technology Development Plan (Windes et. al 2007). One of the key components in the evaluation of these graphite types will be mechanical testing of specimens drawn from carefully controlled sections of each billet. This report is confirmation that the test procedures are in place and approved, and that mechanical testing of graphite under the Baseline Graphite Characterization program has commenced. 


\section{CONTENTS}

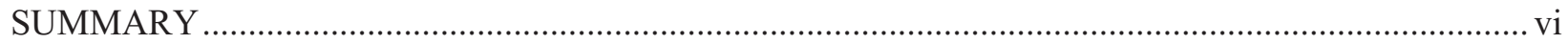

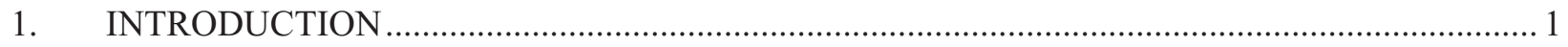

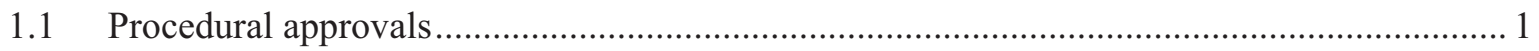

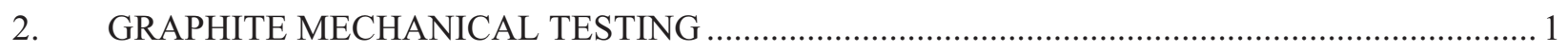

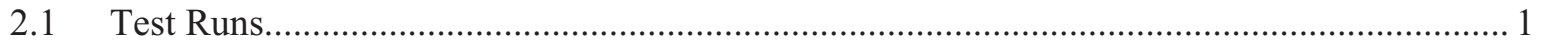

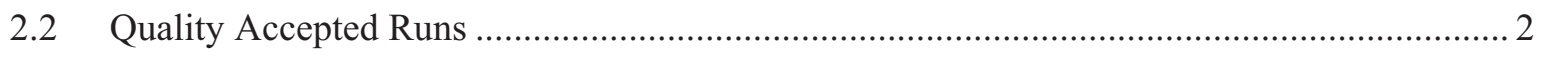

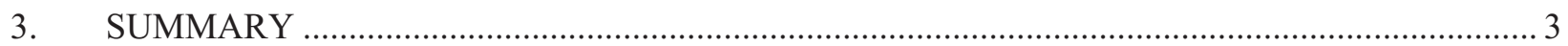

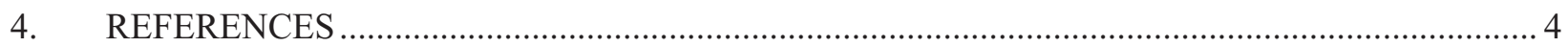

\section{FIGURES}

Figure 1. Test setup per ASTM C 749-08 for the tensile testing of graphite specimens. This specimen was machined from $\mathrm{H}-451$ graphite to the specifications for the first grade of Quality Accepted material that will be run (NBG-18)

Figure 2. The first test on QL-2 material to the accepted procedure. The Figure shows Sample ID 635-14-5-C-P-4-P2-T-F fixtured for a flexural test per ASTM C 651-91 


\section{Baseline Graphite Initial Mechanical Test Report 1. INTRODUCTION}

Characterizing the baseline properties of nuclear-grade graphite will require an extensive amount of mechanical testing from carefully controlled sections of as-produced graphite billets. The test specimens will be evaluated through tensile (ASTM C 749-08), compressive (ASTM C 695-91), and flexural (ASTM C 651-91) tests. The actual testing of specimens from specific billet regions at approved quality level standards requires approval of applicable procedures and a full review of the testing laboratory prior to the commencement of testing at Quality Level 2 (QL-2).

This document reports on the completion of applicable reviews and the commencement of testing of graphite samples for the NGNP Baseline Graphite Characterization program.

\subsection{Procedural approvals}

Testing of samples for the Baseline Characterization program will be carried out per applicable ASTM Standards (see references) and INL LI-444.

The quality assurance review of the mechanical testing of graphite in IRC laboratory B-11 is complete, with observations by the reviewer being addressed. The overall assessment has granted approval for testing per LI-444.

\section{GRAPHITE MECHANICAL TESTING}

The initial testing of graphite specimens was divided into two sections. The first was the verification or scoping runs performed on material from the controlled graphite inventory, but not on actual Quality Accepted material. The second is the reporting of tests on Quality Accepted material based on the satisfactory completion of scoping test runs and approval of the automated test method used to operate the load frame.

\subsection{Test Runs}

Figure 1 shows an example of a test specimen set up for tensile testing per ASTM C 749-08. The sample shown is grade H-451 graphite machined to the ASTM size for NBG-18 graphite (size 123). The test runs allowed a verification of the automated test methods generated in Instron's Bluehill ${ }^{\mathrm{TM}}$ software for the running of tests per applicable ASTM standards for each of the types of testing to be run (tensile, compressive, and flexural). 


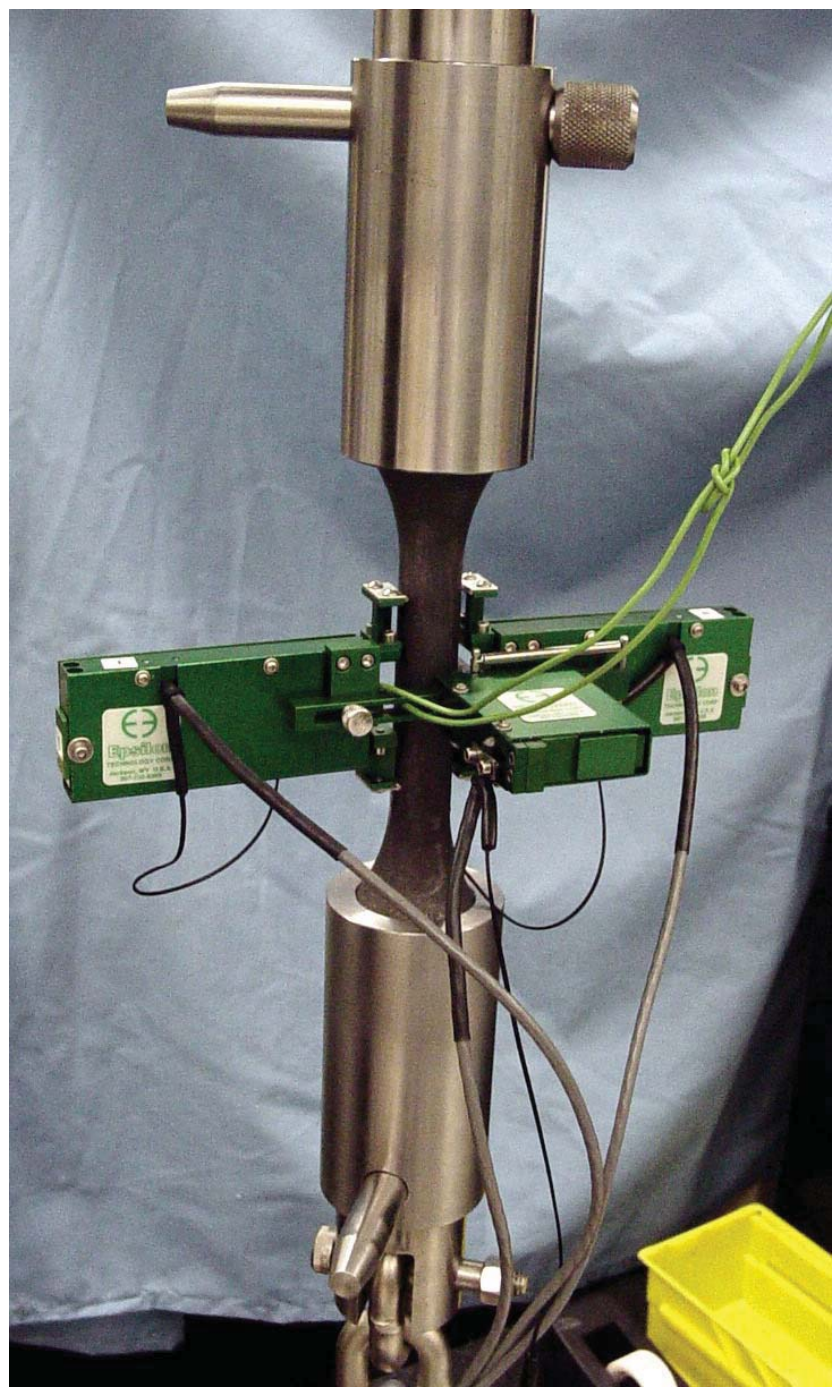

Figure 1. Test setup per ASTM C 749-08 for the tensile testing of graphite specimens. The specimen shown was machined from H-451 graphite to the specifications for the first grade of Quality Accepted material that will be evaluated (NBG-18).

\subsection{Quality Accepted Runs}

This document reports on the commencement of QL-2 testing on graphite samples through the successful completion of flexural testing. Each of the three types of mechanical tests that will be run utilize the same load frames and control software.

Figure 2 shows the first flexural test being set up on Sample ID 635-14-5-C-P-4-P2-T-F. The test has been run, documented, and archived per LI-444. All flexural specimens that have been machined and received have been successfully tested per ASTM C 651-91. 


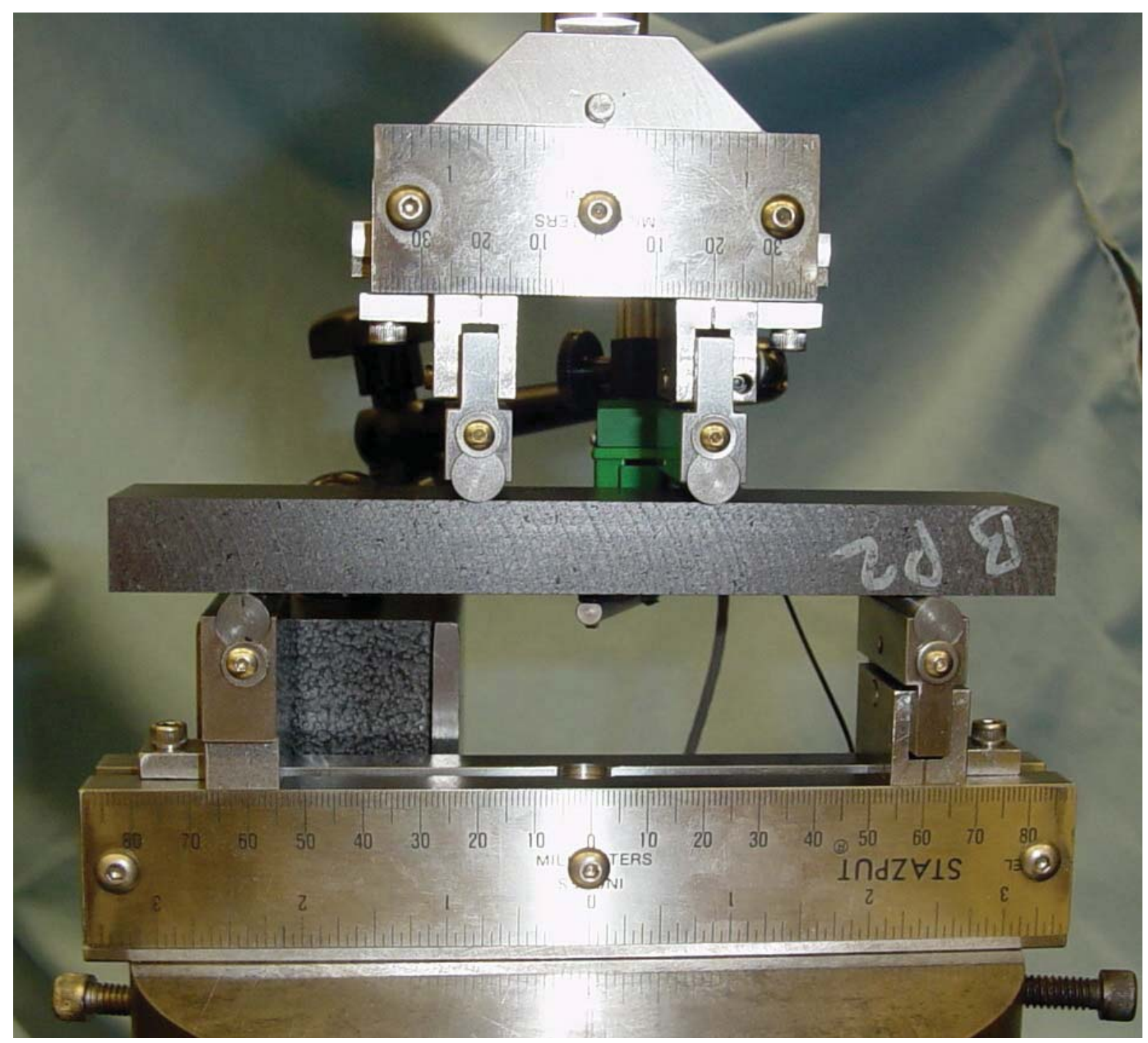

Figure 2. The first test on QL-2 material to the accepted procedure. The Figure shows Sample ID 635-145-C-P-4-P2-T-F fixtured for a flexural test per ASTM C 651-91.

\section{SUMMARY}

The initial mechanical testing on Quality Accepted material has commenced based on the successful review and approval of the governing test procedures and evaluation of the testing laboratory. 


\section{REFERENCES}

Windes, W. E., T. D. Burchell and R. Bratton, 2007, Graphite Technology Development Plan, INL/EXT07-13165, Idaho National Laboratory, Idaho Falls, ID, 35 p.

ASTM C 749-08, "Standard Method for Tensile Stress-Strain of Carbon and Graphite", ASTM International, West Conshohocken, PA, 2008, 12 p.

ASTM C 695-91, "Standard Method for Compressive Strength of Carbon and Graphite", ASTM International, West Conshohocken, PA, Re-Approved 2005, 3 p.

ASTM C 651-91, "Standard Method for Flexural Strength of Manufactured Carbon and Graphite Articles Using Four-Point Loading at Room Temperature", ASTM International, West Conshohocken, PA, Re-Approved 2005, 3 p. 